Supplement of J. Micropalaeontol., 37, 167-180, 2018

https://doi.org/10.5194/jm-37-167-2018-supplement

(C) Author(s) 2018. This work is distributed under

the Creative Commons Attribution 4.0 License.

(c) (1)

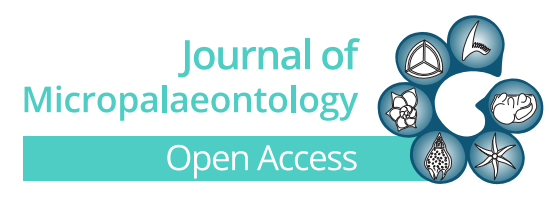

Supplement of

\title{
A humid early Holocene in Yemen interpreted from palaeoecology and taxonomy of freshwater ostracods
}

Munef Mohammed et al.

Correspondence to: Dietmar Keyser (keyser@zoologie.uni-hamburg.de)

The copyright of individual parts of the supplement might differ from the CC BY 4.0 License. 
Archaeological studies give detailed descriptions of the stratigraphy, sedimentology and provide age determinations for sediments of the Dhamar area (Parker et al. 2006; Davies 2006). These publications provide the main sources of our basic data which helped us to select the study area (Wilkinson 1997; Wilkinson et al. 1997; Parker et al. 2006; Davies 2006). Two field trips have been made to the Qa'a Jahran-Dhamar area during November 2013 and March 2014 to collect the material used in the current study.

The studied sections are distributed in three small villages: two sections in Asam village, three sections in Beyt Rashed village and three sections in Wasta village.

Visual inspections of the sediment lithology, grain size, colour, sedimentary structures, and mollusc shell content were carried out during the field work (Fig. 2).

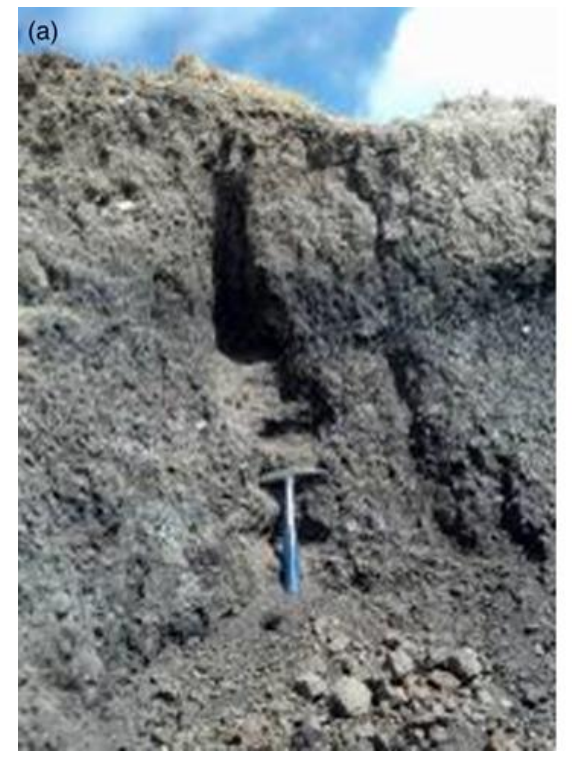

(b)

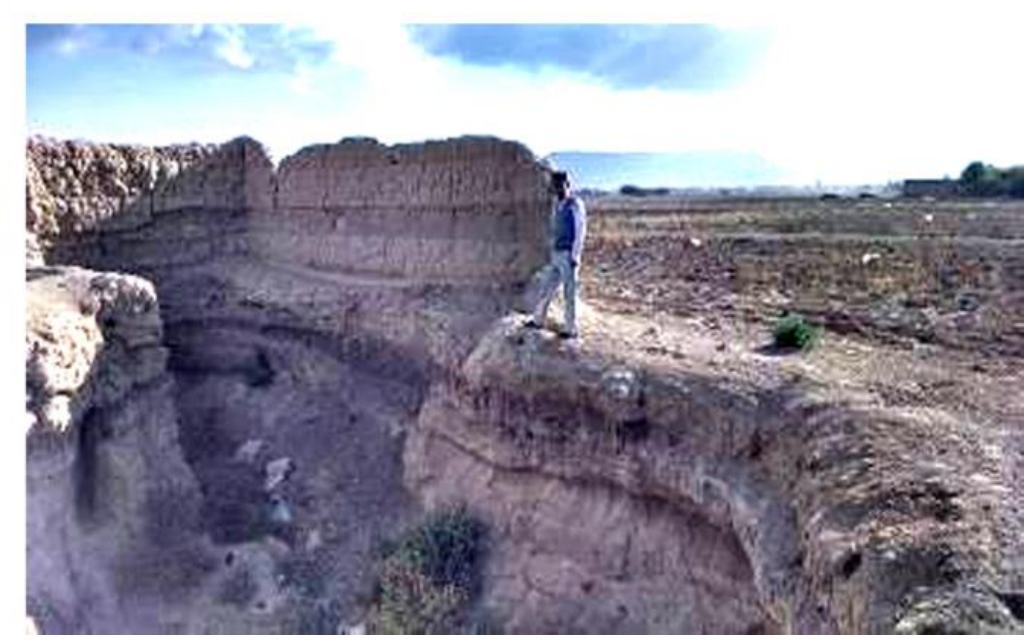

Fig. 1. The stratigraphic sections Asm1 (left) and Was2 (right). 


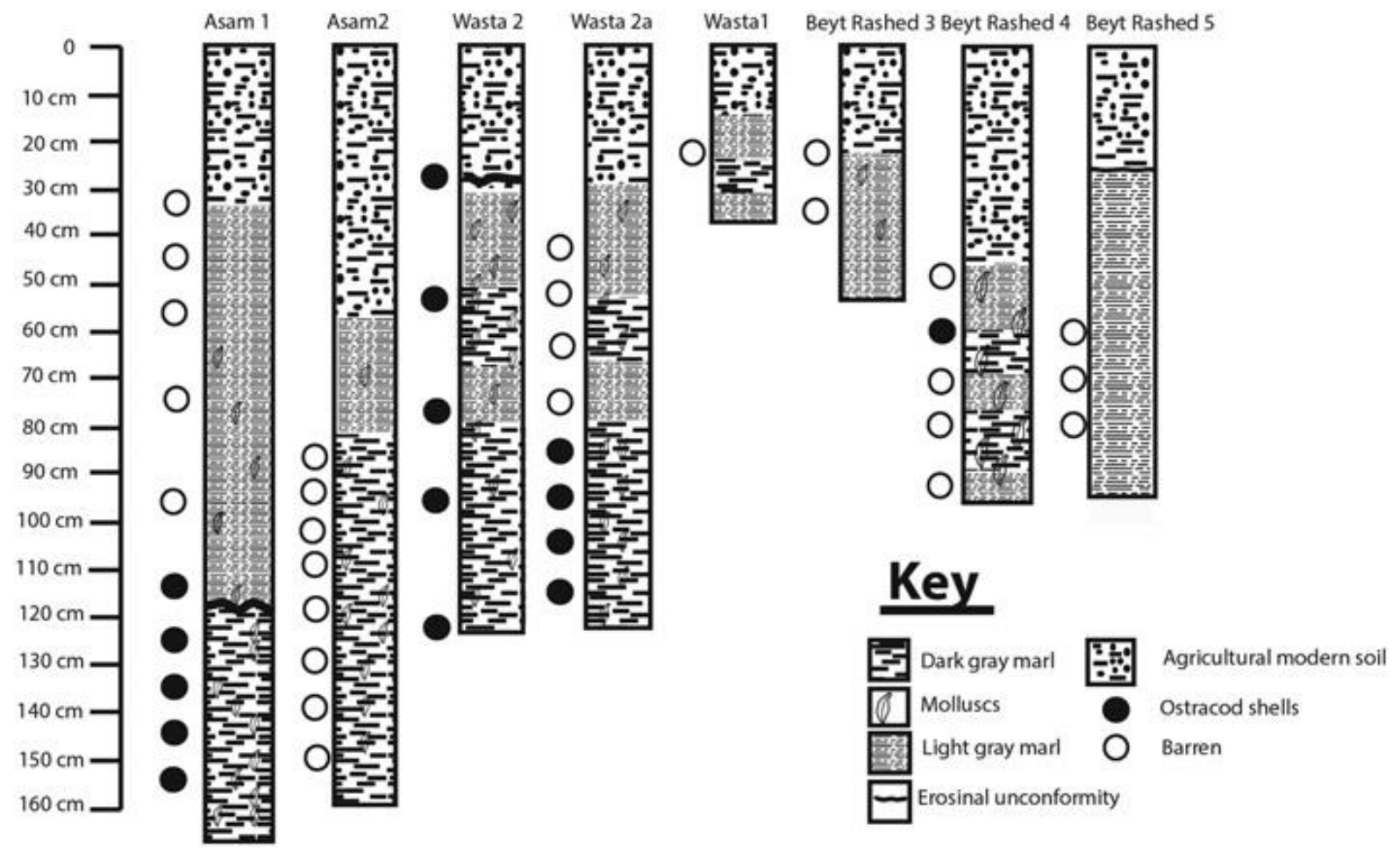

Fig. 2. Lithostratigraphic characters of the studied sections Asam 1,2, Wasta 2,2a,1 and Beyt Rashed 3,4,5 (left to right). 